Int. J. Curr. Res. Med. Sci. (2017). 3(4): 25-33

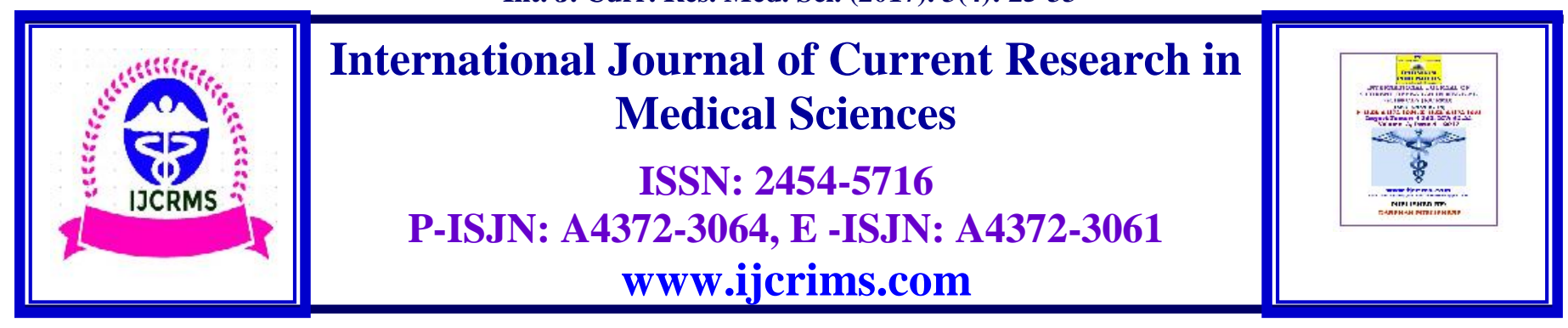

\title{
Comprehensive study regarding intramedullary nailing in fractures of the femoral shaft
}

\author{
*Chandan Gupta, **Dharam Singh, *Dipesh Kumar, ***Radhe Sham Garg, \\ $* * * *$ N.S.Neki \\ *Junior Resident **Assistant Professor,***Professor (Ex), Department of Orthopaedics, \\ Govt. Medical College/ Guru Nanak Dev Hospital, Amritsar, 143001, India \\ **** Professor of Medicine, Govt. Medical College, Amritsar, India
}

Corresponding Author: Dr. Chandan Gupta, Junior Resident, Dept. of Orthopaedics,

Govt. Medical College/ Guru Nanak Dev Hospital, Amritsar, 143001, India

E-mail: doctorchandangupta@gmail.com

\begin{abstract}
Introduction:

Fractures of the shaft of the femur are among the most common fractures encountered in orthopaedic practice. Proximal \& Distal femoral shaft fractures where one cannot get stable three point fixations with conventional nailing can very well be stabilized by interlocking nails. Intramedullary nail being in centre of femur axially can tolerate bending and torsional loads better than plates.

Material and Method:

The present study consisted of 25 cases with fracture shaft of femur of either sex in adults admitted in Guru Nanak Dev Hospital attached to Govt. Medical College Amritsar and were treated with femoral interlocking nailing.

Inclusion criteria:

1. All patients with fracture femur between inferior margin of lesser trochanter and a line transecting the shaft 8 $\mathrm{cm}$ proximal to articular surface of femoral condyles.

2. Closed and grade I open fracture (Gustilo Anderson classification)

Results:

In our study good to excellent results were obtained in $80 \%$ of the cases, fair in $12 \%$ and poor in $8 \%$ of cases.

Conclusion:

It was concluded that closed interlocking nailing of the femur has now become the treatment of choice for closed shaft fracture of femur especially those with high comminution, long spiral and segmental fractures.
\end{abstract}

Keywords: Femur, fracture, intra-medullary, nailing 


\section{Introduction}

Fractures of the shaft of the femur are among the most common fractures encountered in orthopaedic practice. Fracture femur can be largely attributed to violent forces with resultant high mortality and morbidity in patients probably due to associated head and visceral injuries if not attended urgently and adequately. The evaluation and management of patients with femoral shaft fractures continue to evolve on the basis of the improved understanding of the local anatomy, impact of treatment, and biomechanics of fixation techniques. Femoral fracture treatment requires a balancing act of anatomical alignment, stable fixation and early functional restoration of the limb. ${ }^{1}$

Proximal \& Distal femoral shaft fractures where one cannot get stable three point fixations with conventional nailing can very well be stabilized by interlocking nails. Intramedullary nail being in centre of femur axially can tolerate bending and torsional loads better than plates. The locking mechanism provides less tensile and shear than plates. IM interlocking nail is a load sharing device vis-à-vis extramedullary plates causing less cortical osteopenia of stress shielding which is a feature of the load bearing plates. ${ }^{1,2}$

Closed nailing causes no damage to extra periosteal soft tissues and the biological environment around the fracture is least disturbed. Another important feature of the closed intramedullary interlocking nail is the chance for early ambulation of the patient which reduces the complications of prolonged recumbency. The reported clinical morbidity viz damage to abductors, hip capsule after nailing through the trochanteric fossa may result from direct soft tissue injury and may be reduced by choosing the route through the tip of greater trochanter. $^{3}$
All displaced comminuted femoral fractures require internal fixation, one most promising and satisfying is interlocked intramedullary nailing. Conventional plating necessitates extensile approach and periosteal stripping that leads to complications such as delayed healing. Also stress shielding leads to increased chances of refracture after plate removal. ${ }^{4}$

\section{Materials and Methods}

The present study consisted of 25 cases with fracture shaft of femur of either sex in adults admitted in Guru Nanak Dev Hospital attached to Govt. Medical College Amritsar and were treated with femoral interlocking nailing.

\section{Patient selection:}

\section{Inclusion criteria}

1. All patients with fracture femur between inferior margin of lesser trochanter and a line transecting the shaft $8 \mathrm{~cm}$ proximal to articular surface of femoral condyles.

2. Closed and grade I open fracture (Gustilo Anderson classification)

\section{Exclusion Criteria:}

1. Age $<18$ yrs.

2. Open grade II and III fractures

3. Pathological fractures

4. Patients lost in follow up.

All patients were followed monthly till radiological union.. During follow up patients were assessed clinically, radiologically and functionally.

Results were evaluated using Klaus, W. Klemm et al criteria ${ }^{10}$. 
The criteria was as follows:

\begin{tabular}{|l|l|}
\hline EXCELLENT & $\begin{array}{l}\text { Full hip and knee motion } \\
\text { No muscle atrophy } \\
\text { Normal radiographic alignment and no angular deformity. }\end{array}$ \\
\hline GOOD & $\begin{array}{l}\text { Slight loss of hip alignment and knee motion } \\
\text { Shortening }<\mathrm{cm} \quad \text { Muscle atrophy }<2 \mathrm{~cm} \\
\text { Angular deformity }<5\end{array}$ \\
\hline FAIR & $\begin{array}{l}\text { Moderate }(25 \%) \text { loss of hip and knee motion } \\
\text { Muscle atrophy }>2 \mathrm{~cm} \\
\text { Shortening }>2 \mathrm{~cm} \text { o } \\
\text { Angular deformity } 5-10^{\circ}\end{array}$ \\
\hline POOR & $\begin{array}{l}\text { Marked loss of hip \& knee motion } \\
\text { Marked muscle atrophy } \\
\text { Marked shortening } \\
\text { Angular deformity }>10^{\circ}\end{array}$ \\
\hline
\end{tabular}

\section{Results}

The present study consisted of 25 cases with fracture shaft of femur of either sex in adults admitted in Guru Nanak Dev Hospital attached to Govt. Medical College Amritsar and were treated with femoral interlocking nail. These patients were regularly followed and the results of treatment with complications, if any were recorded and analyzed.

In our study good to excellent results were obtained in $80 \%$ of the cases, fair in $12 \%$ and poor in $8 \%$ of cases.

\section{Age and sex distribution:}

The age ranges from above 18 years to 65 years with mean age of 30.76 years. Maximum incidence of fracture was between 20-40 year age group. (14 cases)

Out of 25 cases. 22 patients were males $(88 \%)$ and 3 patients were females (12\%)

Table. 1. Showing age and sex distribution of patients

\begin{tabular}{|c|c|c|c|}
\hline Age in years & Males & Females & Total \\
\hline $18-20$ & 4 & - & 4 \\
\hline $21-30$ & 7 & 2 & 9 \\
\hline $31-40$ & 4 & 1 & 5 \\
\hline $41-50$ & 2 & 1 & 3 \\
\hline $51-60$ & 2 & 1 & 3 \\
\hline $61-70$ & 1 & - & 1 \\
\hline Total & 20 & 5 & 25 \\
\hline
\end{tabular}

2. Union. The results were assessed on clinical examination and radiological appearance based on Donald A. Wiss criteria. ${ }^{5}$

Fracture Union: was defined as the period between operation i.e. interlocking nailing and painless full weight bearing without external support and a radiological signs of healing of fracture (trabeculation seen to cross the fracture in three of the four cortices).

Delayed Union: was considered when the radiographs, failed to demonstrate progressive consolidation between 16-24 weeks after nailing. 
Un-united fracture: was defined by the presence of pain on motion at the fracture site, without radiographic evidence of progressive healing 26 weeks following nailing.

The mean time for union in our study was 18.2 weeks (range being 16 to 26 weeks).
Out of 25 patients 21 patients (84\%) had union in between 16 - 24 weeks where as 4 patients (16\%) which showed delayed union also united at 25 and 26 weeks after dynamization. The mean time of union in our study was 18.2 weeks.

Table 2 showing no. of patients at union

\begin{tabular}{|c|c|c|}
\hline No. of weeks & No. of patients & Percentage \\
\hline $16-24$ & 21 & 84 \\
\hline $24-26$ & 4 & 16 \\
\hline
\end{tabular}

Most of the patients achieved acceptable level of prefracture activity at the time of their bony union except the patients who had restriction of movements at knee joint and other associated fractures.

\section{3. ). Knee flexion}

Out of 25 patients ,17 patients (68\%) had full range of movements, 3 patient $(12 \%)$ had mild restriction of movements(100-130), 2 patients (8\%) had moderate range of movements (movement loss more than $25 \%$ ), 3 patients (12\%) had severe restriction of movements had flexion of $30^{\circ}$.

Table 3 Showing patient distribution according to their knee flexion

\begin{tabular}{|c|c|c|}
\hline Knee flexion & No of patients & Percentage \\
\hline Full (130 and more) & 17 & 68 \\
\hline Mild resriction $(120)$ & 3 & 12 \\
\hline Moderate $(100-30)$ & 2 & 8 \\
\hline Severe & 3 & 12 \\
\hline
\end{tabular}

\section{Discussion}

The treatment of fracture shaft of femur has evolved from the old conservative management to the most recent methods of interlocking nails. This is the era of biological fixation. Interlocking nails have greatly expanded the indications for closed IM nailing of femoral fractures. Early mobilization following fractures of the femoral shaft has been shown to have a significant advantage in terms of both joint mobility and economic impact which has very well attained by the use of interlocking nails.

\section{Age}

Majority of our patients were in the age group 2130 years. The youngest being 18 years and oldest being 65 years. The mean age of patients in our study was 31.24 which is comparable to the mean age in study by Thoreson ${ }^{5}$ of 48 cases is 28 , by wiss et al ${ }^{7}$ is 29 yrs and by Deepak et al ${ }^{6}$ is 27.4 .

The higher incidence of these injuries in this age group can be owed to their engagement in activities relating to travel and outdoor works. Lesser incidence of patients in the older age group in our study was mainly because of less active lifestyle in this age group of the patients. We have not included patients less than 18 years because of potential damage to the epiphyseal plate injuries in these patients which often is not united in this age group. 
Int. J. Curr. Res. Med. Sci. (2017). 3(4): 25-33

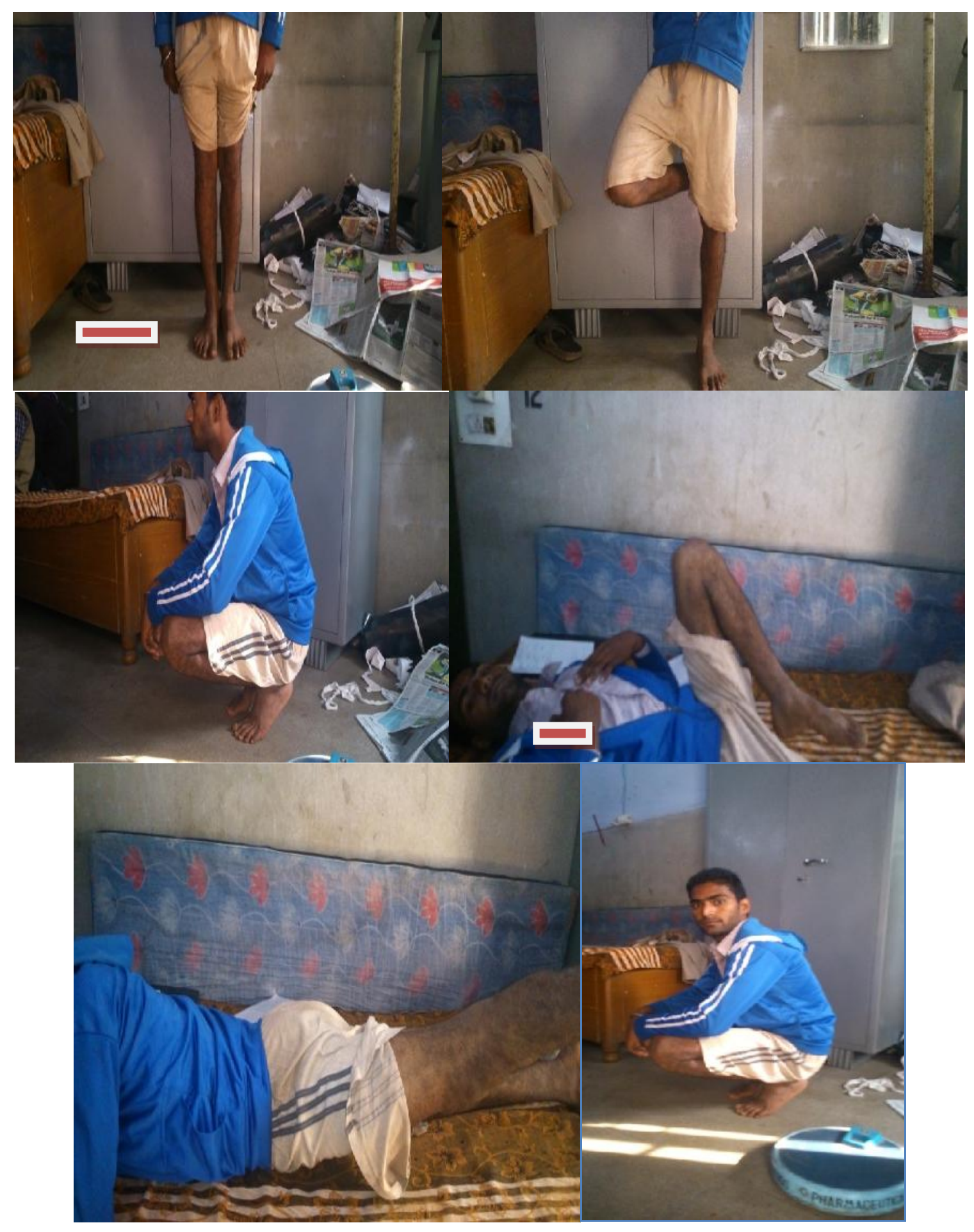

Photographs showing full range of movements at full union. 
Int. J. Curr. Res. Med. Sci. (2017). 3(4): 25-33

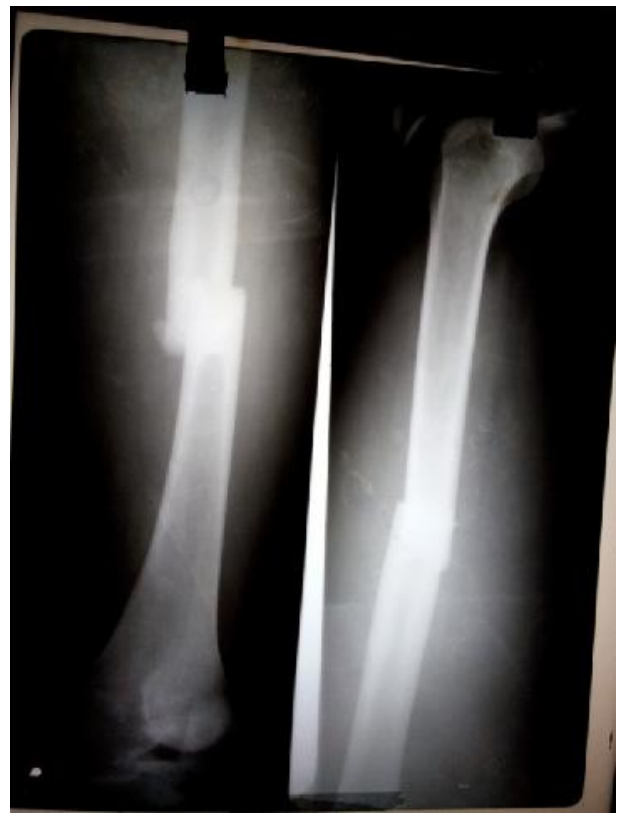

(a)

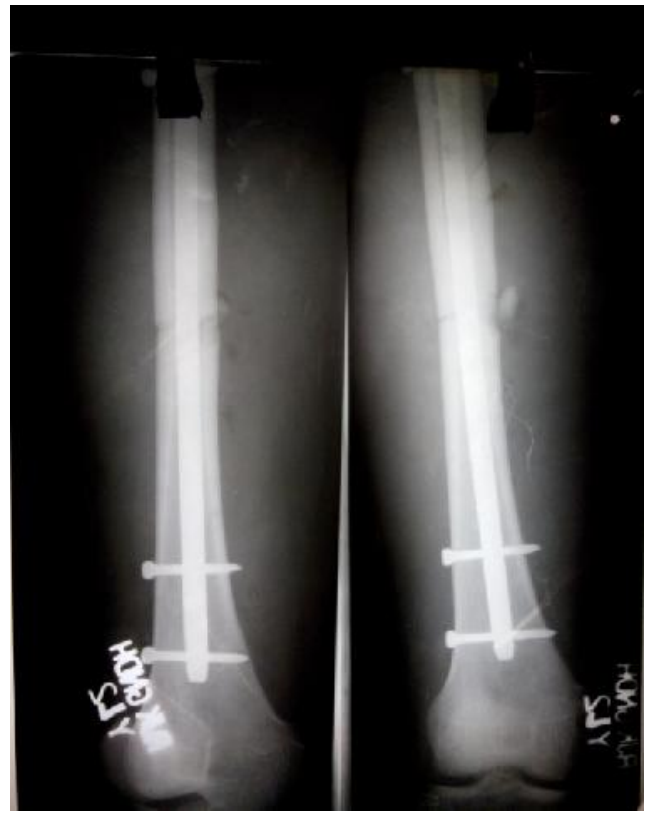

(b)

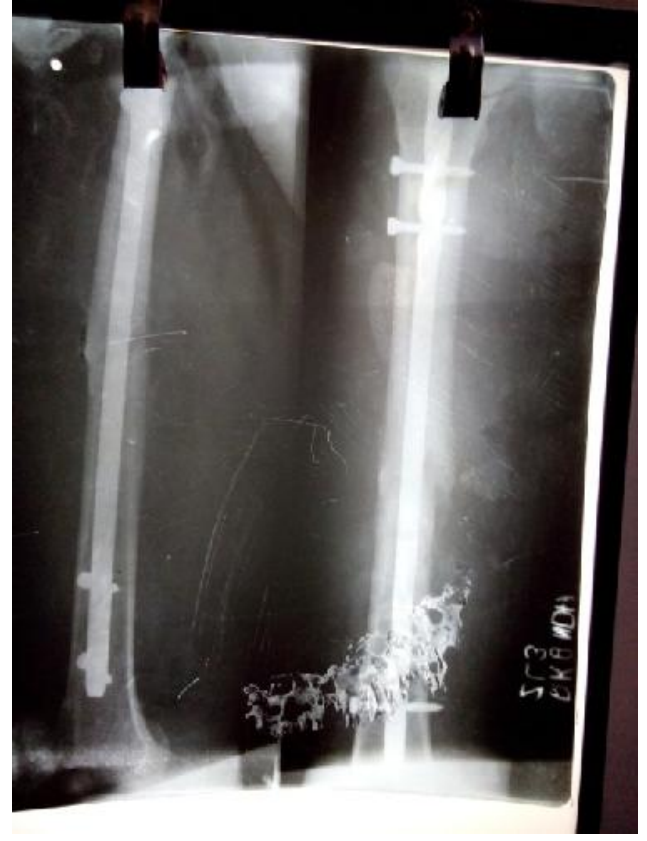

(c)

a).showing pre operative $x$-ray

b).showing post operative $x$-ray c)showing complete union at 18 weeks.

Sex

In our study of 25 cases, there were 20 males $(80 \%)$ and $5(20 \%)$ female patients which is comparable to the other studies by Thoreson ${ }^{5}$,
Wiss et $\mathrm{al}^{7}$ and Deepak et $\mathrm{al}^{6}$. The predominance of male patients in our study is probably due to the fact that males are more active than females in the outdoor activities as still the males are the sole earner of bread in most of the Indian families. 


\section{Mode of Injury}

In our study the mode of injury was road side accidents $(76 \%)$, due to falls (16\%), and alleged assault (8\%). RSA being the most common mode of injury is also comparable to the other studies. (Wisset $\mathrm{al}^{7}$, Thoreson ${ }^{5}$ and Christie et al ${ }^{8}$ and Deepak et al ${ }^{6}$.

The fact that high velocity trauma required for such fractures is supported by our observations that road side accidents are the major cause of these fractures.

\section{Side}

In our series right sided fractures(16 cases ,64\%) were more common which is comparable to other series of Johnson and Greenberg ${ }^{9}$, of Wiss et al ${ }^{7}$ where right sided comminuted fractures were more common and Deepak et al ${ }^{6}$ where right side constituted $60 \%$ of the fractures.

\section{Pattern of Fractures}

In our series the most common pattern is transverse (14 patients (56\%), followed by comminuted (7 patients (28\%) and oblique fractures (4 patients (8\%) Most common is A3 followed by B1 and A2.

In the study of thoresen5right side comminuted fractures were more common followed by transverse and then the spiral fractures

In the series of wiss et al ${ }^{7}$ comminuted fractures predominated.

In the series of Deepak et al ${ }^{6}$, comminuted fractures dominated followed by transverse fracture.

The high incidence of these high grade (transverse as well as comminuted) fractures is due to high velocity of trauma associated with these fractures.

\section{Associated Injuries}

In our series associated bony fracture present in 7 cases $(28 \%)$.
The associated injuries signify the high intensity of trauma involved in these fractures. This trend has been observed in other studies as well. (Wiss et al ${ }^{7}$ and Thoreson ${ }^{5}$ and Deepak et al ${ }^{6}$ )

\section{Injury surgery duration}

Patients were operated between 1 to 6 days with average of 2.2 days. This is comparable to western literature (Christie et al ${ }^{8}$ most of the fractures fixed within 48 hours ).The delay in surgery of some patients was due to associated other injuries and other medical comorbidities with delayed anesthetic fitness.

The patients who were operated at $>3$ days from injury had difficulty in reduction and prolonged surgery duration.

\section{Nail Length}

Commonest length and nail of diameter used $38 * 9,38 * 10,40 * 9$ TO $38 \mathrm{~cm} * 9 \mathrm{~mm}, 38 \mathrm{~cm} * 10$ $\mathrm{mm}, 40 \mathrm{~cm} * 9 \mathrm{~mm}$. Which is similar in study by Deepak et al6.This is in contrast to western literature where most of the nails were larger diameter (12 and $13 \mathrm{~mm}$ ). The skeletal framework of Indian population is on the lower side compared with the western population. This is probably the reason of using a smaller diameter nail in our study.

\section{Union}

In the series of Donald wiss ${ }^{7}$ union was obtained at 20 weeks.

In the series of Thoresen et al ${ }^{5}$ of 48 cases ,mean time to union was 16 weeks.

In the series of Christie et al ${ }^{8}$, average time of union was 17 weeks.

Average time of union in series by Johnson, et $\mathrm{al}^{9}$ is 18.4 weeks.

Average time of union by Deepak et al ${ }^{6}$ is 16.5 weeks.

In our study time to union ranged from 16 to 26 weeks with an average of 18.2 weeks which is 
comparable. However 2 cases took time more than 24 weeks.

Delayed union was seen in patients having highly comminuted and compound fractures. There is no significant change in union rates when compared to age, sex and location of fractures .

Complications of nailing range from infections, mal-alignment, shortening, non union and failure of implant.

In the series of Donald wiss ${ }^{7}$ the infection rate (superficial) after closed nailing is $0.9 \%$, Angulation in any plane $>10$ is $2.5 \%$ and $1.8 \%$ shortening.

In the series of Thoreson ${ }^{5} 6.25 \%$ had varus alignment, $2 \%$ had valgus malalignment, $2 \%$ had internal rotation and $4 \%$ had external rotation deformity. $6.7 \%$ cases had shortening $>1 \mathrm{~cm}$. No case of infection and impaired healing was seen.

In the series of Christie ${ }^{8} 0.8 \%$ had superficial infections, $1.6 \%$ had nonunion, $0.8 \%$ had external deformity and $1.6 \%$ had delayed union.

In the series of Deepak et al ${ }^{6}$ incidence of delayed union was $6.6 \%$ and shortening in 13.33 $\%$ of cases.

In our series there was no case of non-union, valgus alignment $\left(<5^{\circ}\right)$ in 2 cases $(8 \%)$, varus $\left(<5^{\circ}\right)$ alignment in 1 case (4\%), shortening of $1.5 \mathrm{~cm}$ in two patients $(8 \%)$ and $1 \mathrm{~cm}$ in 3 patients $(12 \%)$. 2 cases had delayed union $(8 \%)$.

There was no case of implant failure, 2 patients had distal bolt breakage which required removal later.

Superficial infections in 2 cases $(8 \%)$. There was no case of deep infection present. Superficial infection got treated with antibiotics within 12 days of surgery.

Sporadic pain in the knee in 2 patients and hip in 4 patients after union.

The higher incidence of complications like superficial infections, shortening may be attributed to higher number of patients with lower socioeconomic status and lower compliance to treatment. Also the higher incidence of comminuted fractures in the study may be the cause of more complications in our study.

Average duration of surgery is 100 minutes ranging from 75-150 minutes which is comparable to the study by Chistie et al ${ }^{8}$.

The duration of surgery was maximum in patients undergoing surgery on or after 4th day of the injury.

\section{Knee range of movements}

In our study average knee flexion is $118.6^{\circ}$ which is less than that of Thoreson ${ }^{5}$ which is $127^{\circ}$ and that of Wiss et al ${ }^{7}$ which is $120^{\circ}$. This may be due to associated upper end tibia and patella fractures in 2 patients each.

\section{Results}

According to Kleims criteria ${ }^{10}$ in our study, 15 pts had excellent (60\%), 5pts had good (20\%), 3 pts $(12 \%)$ had fair and 2 pts had poor $(8 \%)$ response.

Our result is comparable to the study of Deepak et $\mathrm{al}^{6}$ as they used the same criteria. They showed excellent results in $66.6 \%$, good in $20 \%$ of cases, fair in $10 \%$ of cases and poor in $3.4 \%$ of the cases.

In study by Thoresen et $\mathrm{al}^{5}$, excellent were 30 patients $(62.5 \%), 8$ as good $(16.66 \%), 7$ as fair $(14.5 \%)$ and 2 as poor $(4.1 \%)$ out of total 48 cases.

The higher incidence of poor and fair results in our study as compared to above studies may be due to greater knee stiffness because of associated ipsilateral upper end tibia and patella fractures

\section{Conclusion}

It was concluded that closed interlocking nailing of the femur has now become the treatment of choice for closed shaft fracture of femur especially those with high comminution, long spiral and segmental fractures. Interlocking nail offers the patients the added advantage of early joint mobilization, early muscle rehabilitation shorter hospitalization and most important early return to work and pre-fracture state as the incidence is more in working age group. Restoration of anatomic length alignment, 
of comminuted fractures is possible and it extends the use of intramedullary nail to more proximal and distal fractures. Closed interlocking nail reduces the incidence of complication like infection, malunion, non-union. The rate of union compared to other modalities of treatment is excellent.

\section{References}

1. Matthew I, Rudloff. Fracture of the lower extremity. In: Campbell's Operative Orthopaedics, 2013; 12: 2702-716.

2. Wolinsky P, Tejwani N, Richmond JH, Koval KJ, Egol K, Stephen DJ.Controversies in intramedullary nailing of femoral shaft fractures. Instr Course Lect2002; 51:291-303.

3. Ansari Moein CM, Verhofstad MH, Bleys RL, van der Werken C. Soft tissue anatomy around the hip and its implications for choice of entry point in antegrade femoral nailing.Clin Anat 2008; 21(6):568-74.

4. Chan DS, Burris RB, Erdogan M, Sagi HC. The insertion of intramedullary nail locking screws without fluoroscopy: a faster and safer technique. J Orthop Trauma 2013; 27(7):3636.

5. Thoresen BO, Alho A, Ekeland A, Strømsøe $\mathrm{K}$, Follerås G, Haukebø. A Interlocking intramedullary nailing in femoral shaft fractures .a report of 48 cases. J.B.J. S Am 1985; 67 (A): 131320.

6. Deepak MK, Jain K, Rajamanya KA, Gandhi PR, Rupakumar CS, Ravishankar R. Functional outcome of diaphyseal fractures of femur managed by closed intramedullary interlocking nailing in adults.Ann Afr Med. 2012; 11(1):52-7.

7. Wiss DA, Fleming CH, MattaJM, Clark D Comminuted and rotationally unstable fractures of the femur treated with an interlocking nail. ClinOrthopRelat Res. 1986; (212):35-47.

8. Christie J, Court-Brown C, Kinninmonth AW, Howie CR. Intramedullary locking nails in the management of femoral shaft fractures. J Bone Joint Surg Br. 1988 ; 70(2):206-10.

9. Johnson KD, Johnston DW, Parker B. Comminuted femoral-shaft fractures: treatment by roller traction, cerclage wires and an intramedullary nail, or an interlocking intramedullary nail. J Bone Joint Surg Am. 1984; 66(8):1222-35.

10. Klemm KW, Börner M. Interlocking nailing of complex fractures of femur and tibia. Clin Orthop Relat Res 1986; 212: 89-100.

\begin{tabular}{|c|l|}
\hline \multicolumn{2}{|c|}{ Access this Article in Online } \\
\hline Quick Response Code & Website: \\
\hline & Www.ijcrims.com \\
\hline
\end{tabular}

How to cite this article:

Chandan Gupta, Dharam Singh, Dipesh Kumar, Radhe Sham Garg, N.S.Neki. (2017). Comprehensive study regarding intramedullary nailing in fractures of the femoral shaft. Int. J. Curr. Res. Med. Sci. 3(4): 25-33.

DOI: http://dx.doi.org/10.22192/ijcrms.2017.03.04.004 